\title{
Comportamento dos radionuclídeos potássio, urânio e tório em relação à granulação dos depósitos cenozóicos que capeiam o granito Serra do Carambeí - Pr
}

\section{Behavior of the radionuclides potassium, uranium and thorium in relation to the particle size of cenozoic sediments that cover the Serra do Carambeí granite - Pr}

\author{
Luiz Carlos Godoy \\ Universidade Estadual de Ponta Grossa \\ André Virmond Lima Bittencourt \\ Leonardo José Cordeiro Santos \\ Francisco José Fonseca Ferreira \\ Universidade Federal do Paraná
}

\begin{abstract}
Resumo: Situado no sudeste do estado do Paraná, o Granito Serra do Carambeí contém concentrações relativamente elevadas de urânio e de tório, conhecidas desde a década de 1970 por meio de levantamentos gamaespectrométricos. Ensaios radioquímicos (análise por ativação neutrônica - AAN) realizados em 61 amostras de rochas e de coberturas cenozóicas confirmaram seu caráter radioanômalo. Dados granulométricos de amostras das coberturas cenozóicas indicam que o tório e o potássio apresentam correlações moderadas (positivas e negativas) com as diversas classes granulométricas. Porém, quanto ao urânio, as baixas correlações não permitem estabelecer qualquer vinculação com o tamanho da partícula.
\end{abstract}

Palavras-chave: Granito Serra do Carambeí. Coberturas cenozóicas. Análises radioquímicas. Ensaios granulométricos.

\begin{abstract}
Situated in the southeastern region of the Parana State, the Serra do Carambeí Granite contains relatively high concentrations of uranium and thorium which since the 1970s have been detected by gamma-ray spectrometric surveys. Rocks and Cenozoic sediment samples, collected at 61 different locations of this granite, were subjected to radiochemical essays (neutron activation analysis - NAA) confirming the occurrence of radioactive anomalies in them. Granulometric data from Cenozoic sediments samples indicate that thorium and potassium present moderate correlations (positive and negative) with different particle size ranges of these constituents' unconsolidated caps. However, as far as uranium is concerned, the correlations are weak not allowing the establishment of any relationship between concentrations of ${ }^{238} \mathrm{U}$ and particle size.
\end{abstract}

Keywords: Serra do Carambeí Granite. Cenozoic sediments. Radiochemical analysis. Granulometric tests. 


\section{INTRODUÇÃO}

Desde a sua formação, a Terra sempre esteve submetida a doses variáveis de radioatividade natural, provenientes tanto do decaimento de radionuclídeos presentes nas rochas e solos, quanto da radiação cósmica e da interação desta com gases atmosféricos. Mais recentemente, como resultado de atividades tecnológicas que processam isótopos radioativos ou utilizam materiais e compostos contendo isótopos radiogênicos (fabricação de fertilizantes agrícolas, explotação de rochas para revestimentos e outras), tem-se verificado, em certas regiões, um aumento e uma concentração significativa nos níveis de radioatividade natural. Além disso, emanações radioativas devido a isótopos artificiais (usinas nucleares de geração de energia, testes e acidentes nucleares) representam riscos potenciais de poluição antropogênica.

A maior parte da radiação ionizante que afeta o ser humano, no entanto, deve-se ao decaimento de radionuclídeos naturais como $\mathrm{o}^{40} \mathrm{~K}$ e aos pertencentes às séries do ${ }^{238} \mathrm{U}$ e do ${ }^{232} \mathrm{Th}$. Esses radioisótopos, amplamente difundidos na crosta terrestre, respondem por cerca de $60 \%$ a $70 \%$ da radiação ionizante total que atinge o homem. (NCRP, 1987; ATSDR, 1999; TAUHATA et al., 2003). No entanto, por ocorrerem normalmente em baixas concentrações, geralmente não representam risco radiológico aos seres humanos ou à biota.

Dados da literatura indicam que a abundância média do urânio na crosta terrestre oscila entre 2 e 3 ppm, a do tório entre 8 e $12 \mathrm{ppm}$ e a do potássio entre $2 \mathrm{e}$ 2,5\%.(DICKSON; SCOTT, 1997; WILFORD et al., 1997; MINTY, 1997; IAEA, 2003a; BONOTTO, 2004). Apesar dos reduzidos teores médios, e por se tratarem de elementos litófilos, determinadas rochas, principalmente ígneas ácidas (BONOTTO, 2004; ULBRICH et al., 2009), podem apresentar-se enriquecidas nesses elementos. É o caso do Granito Serra do Carambeí, cujas concentrações relativamente elevadas de urânio e de tório, conhecidas desde a década de 1970 por meio de levantamentos gamaespectrométricos, foram estudas por diversos pesquisadores. (PINTO-COELHO, 1986; PINTO-COELHO, 1987; PINTO-COELHO; SIEDLECKI, 1988; RIFFEL, 2000; GUIMARÃES, 2000; GUIMARÃES et al., 2001; FERREIRA et al., 2001; RIFFEL et al., 2001; RIFFEL, 2001; FERREIRA et al., 2005).

Visando um melhor conhecimento da distribuição desses radionuclídeos, foram coletadas 61 amostras de rochas e de coberturas cenozóicas inconsolidadas (manto de alteração e depósitos aluviais), principalmente na área de abrangência do Granito Serra do Carambeí. Os ensaios radioquímicos pelo método de análise por ativação neutrônica (AAN) visaram determinar as concentrações de $\mathrm{K}$, U e Th, enquanto amostras do manto de alteração e de depósitos aluviais foram submetidas, ainda, a ensaios granulométricos.

Portanto, este trabalho tem por objetivo analisar a distribuição espacial dos radionuclídeos em rochas e em coberturas cenozóicas na região do Granito Serra do Carambeí e estabelecer relações das concentrações de K, U e Th e as diferentes classes granulométricas das coberturas cenozóicas.

A área de estudo situa-se no sudeste do estado do Paraná, porção oeste da bacia da represa de Alagados, abrangendo parcialmente os municípios de Carambeí, Ponta Grossa e Castro (Figura 1). A maior parte da área pertence ao Primeiro Planalto Paranaense e pequena porção, no extremo sudoeste, ao Segundo Planalto. Possui formato retangular orientado na direção $\mathrm{NE}$, com $14 \mathrm{~km}$ de comprimento por 7,3 
$\mathrm{km}$ de largura, abrangendo a totalidade do Granito Serra do Carambeí e unidades limítrofes (Complexo Granítico Cunhaporanga e Formação Furnas).

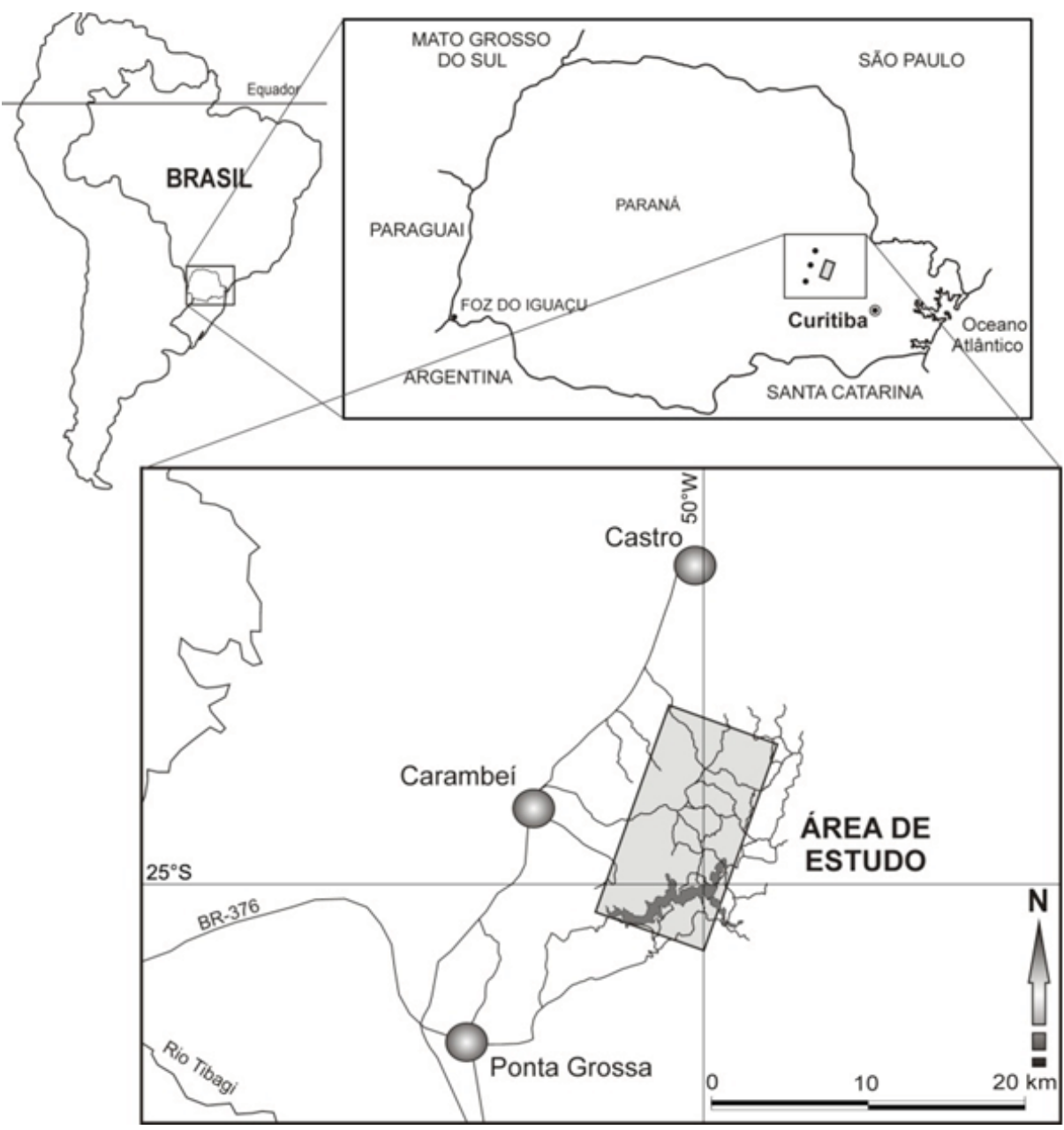

Figura 1 - Localização da área de estudo com as principais vias de acesso Org: GODOY, 2010

\section{GEOLOGIA REGIONAL E LOCAL}

A geologia da região em que se localiza a área de estudos inclui unidades com idades entre o Neoproterozóico e o JuroCretáceo (Figura 2), capeadas por depósitos inconsolidados cenozóicos.

O Neoproterozóico é representado pelo Complexo Granítico Cunhaporanga, ao qual pertence o Granito Serra do Caram- beí, que compõe a quase totalidade da área objeto da presente pesquisa. Rochas do Grupo Castro, de idade eocambriana a eordoviciana, afloram a oeste, porém não ocorrem na área de estudo. No extremo sudoeste ocorrem rochas da Formação Furnas, de idade eossiluriana a devoniana. Todas estas litologias são seccionadas por inúmeros diques de rochas básicas, principalmente de diabásio, pertencentes ao magmatismo Serra Geral (Mesozóico).

\subsection{Complexo Graní- tico \\ Cunhaporanga}

O Complexo Granítico Cunhaporanga constitui um batólito de forma alongada com eixo maior na direção NE-SW que aflora desde a região da represa de Alagados (Ponta Grossa - PR), onde é sobreposto por arenitos da Formação Furnas, até Sengés - PR, onde novamente é encoberto pela mesma unidade.

É caracterizado por uma grande diversidade de tipos granitóides, descrita e mapeada como unidades litoestratigráficas informais e formais. (GUIMARÃES, 2000). As unidades informais ocorrentes na área de estudo são os domínios petrográficos Serra Abaixo-Alagados (NPcsaa) e JotubaPitangui (NPcjp), enquanto a unidade formal corresponde ao Granito Serra do Carambeí, representado por álcali-feldspato granitos $\left(\mathrm{NPcsc}_{1}\right)$ e pela fácies de borda $\left(\mathrm{NPcsc}_{2}\right)$ (Figura 2). 
O domínio petrográfico Serra AbaixoAlagados, constituído dominantemente por granitóides equigranulares médios classificados como monzogranitos e, subordinadamente, granodioritos, ocorre ao sul e a sudeste da represa de Alagados. A composição mineral inclui, como minerais essenciais, plagioclásio, feldspato potássico, anfibólio, biotita e titanita, além de apatita, zircão e opacos (principalmente magnetita), como minerais acessórios. (Ibidem).

Ao norte da represa de Alagados, em contato com o Granito Serra do Carambeí, tem-se o domínio petrográfico Jotuba-Pitangui, constituído por granitóides classificados como monzogranitos a granodioritos. São rochas porfiríticas a equigranulares, contendo fenocristais de feldspato potássico que ultrapassam $3 \mathrm{~cm}$ de aresta. A cor é acinzentada e a estrutura varia de maciça (Rincão do Cafequi) a foliada (Campina do Jotuba). Os principais minerais são: anfibólio, feldspatos, quartzo, titanita e allanita. (Ibidem).

O Granito Serra do Carambeí aflora à margem norte da represa de Alagados, quase integralmente no município de Carambeí - PR. Constitui um corpo relativamente homogêneo, de formato elíptico, com eixo maior na direção aproximada N30E, aflorante no extremo sudoeste do Complexo Granítico Cunhaporanga (Figura 2).

A porção central deste granito, tipicamente alasquítica, corresponde aos álcalifeldspato granitos - NPcsc 1 (GUIMARÃES, 2000), onde foram constatadas as maiores concentrações de K, U e Th. São rochas de cor rósea a acinzentada quando frescas, textura equigranular fina a grossa e conteúdo mineral constituído principalmente por feldspato potássico e quartzo, além de minerais acessórios como biotita, hematita, fluorita e zircão.

Envolvendo os álcali-feldspato granitos tem-se a fácies de borda - NPcsc2 (Ibidem), constituídas por granitóides de textura heterogênea que varia de equigranular média a grossa à porfirítica de matriz fina. São rochas em geral muito alteradas, cuja cor varia de acinzentada a marromesverdeada. Como minerais essenciais ocorrem principalmente feldspatos potássicos, plagioclásios e quartzo, enquanto os principais acessórios são a biotita, a fluorita e a apatita. (Ibidem).

\subsection{Formação Furnas}

A Formação Furnas, unidade basal do Grupo Paraná, pertence à unidade aloestratigráfica Supersequência Paraná (MILANI et al., 2007), ocorrente no extremo sudoeste da área de pesquisa (Figura 2). É essencialmente quartzosa, formada de arenitos de cor clara (branca, amarelada, acinzentada ou arroxeada), com grãos subangulosos a subarredondados, regularmente selecionados e com matriz caulinítica, contendo pequena quantidade de grãos de feldspatos caulinizados. Sua idade é considerada como neossiluriana a eo-devoniana. (ASSINE, 1996; BERGAMASCHI, 1999).

Afloramentos pertencentes à sequência basal da Formação Furnas são encontrados às margens da represa de Alagados onde, além de conglomerados - comuns nesta porção da formação -, ocorre estreita camada pelítica de cor cinza, com cerca de 10 cm de espessura, intercalada nos arenitos médios a grossos (Figura 4).

\subsection{Rochas intrusivas básicas a inter- mediárias}

As litologias regionais, anteriormente referidas, são seccionadas por inúmeras intrusões, principalmente de rochas básicas (diabásio), pertencentes ao magmatismo Serra Geral - Supersequência III. Ocorrem na forma de diques com idades entre 
$134,1 \pm 1,3$ Ma e 130,5 $\pm 2,8$ Ma (TURNER et al., 1994) e a grande incidência dos mesmos na área é justificada pela sua localização próxima ao eixo do Arco de Ponta Grossa, ou seja, ao longo da faixa de maior inflexão do arco, de sorte que tais diques encontram-se intrudidos nas fraturas distensivas

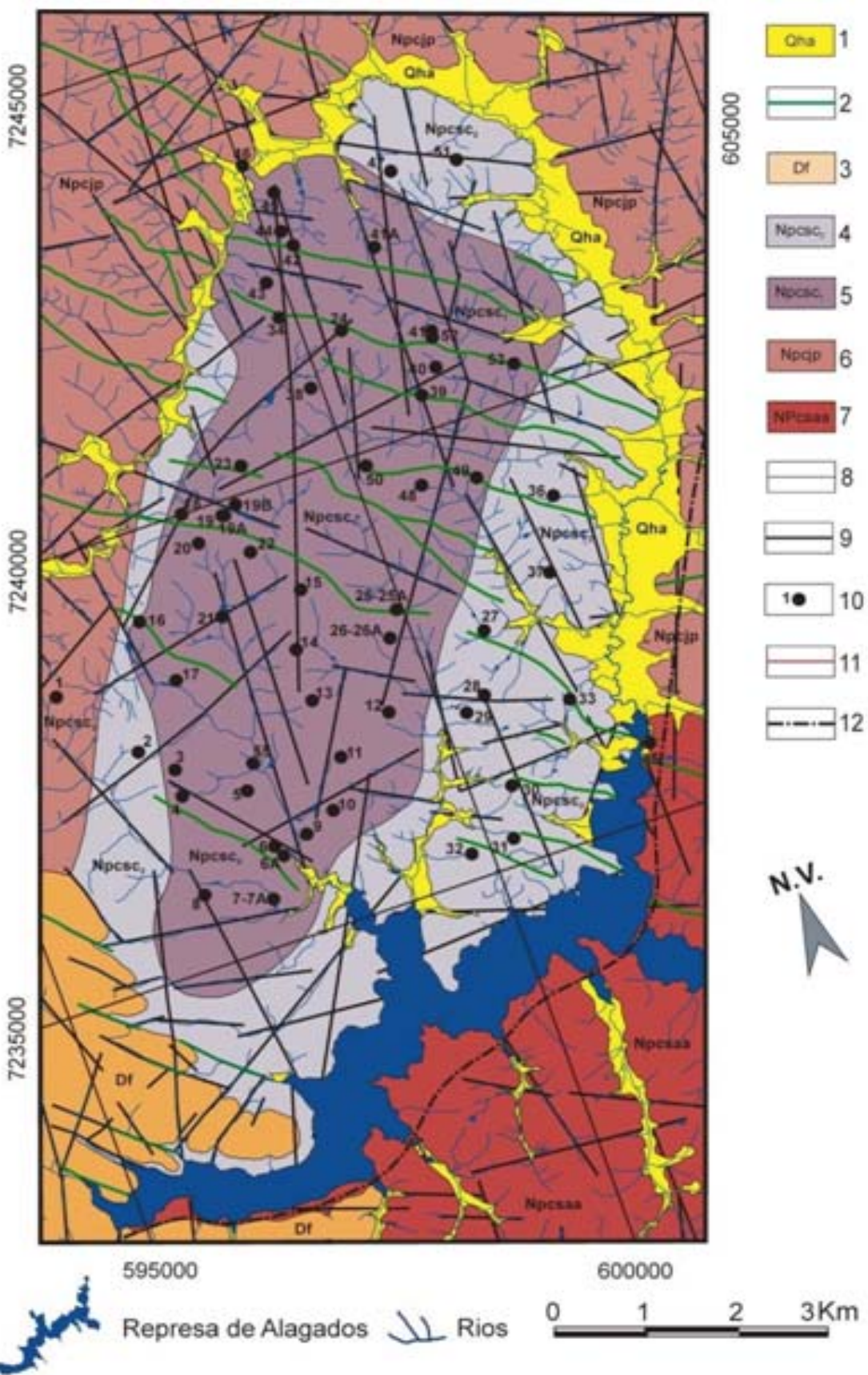

de direção geral NW-SE originadas pelo arqueamento. As espessuras desses diques variam de submétricas a decamétricas. Em geral, apresentam cor cinza-escura à preta devido à abundância de minerais ferromagnesianos e granulação milimétrica a submilimétrica.

Figura 2 - Mapa geológico da área de estudo indicando a localização das estações de amostragem Fonte: Adaptado de GUIMARÃES, 2000; MINEROPAR, 2006a, b

1) Depósitos aluviais quaternários; 2) Diques; 3) Formaçào Furnas; 4) Granito Serra do Carambei (GSC) - Álcali-feldspato granitos (Npcsc); 5) GSC - Fácies de borda (Npcsc) ; 6) Complexo Granitico Cunhaporanga (CGC) - Dominio Jotuba-Pitangui (Npcjp); 7 ) CGC - Dominio Serra Abaixo-Alagados (Npcsaa); 8) Contato geológico; 9) Falha/fratura; 10) Estaçós de amostragem de rochas, manto de alteraçào e aluvióes; 11) Estradas: 12 Ferrovia. 


\subsection{Coberturas cenozóicas}

As coberturas cenozóicas da área incluem depósitos eluviais, coluviais e aluviais, cujas composições variam de acordo com os tipos litológicos aos quais estão relacionados, bem como em função das características climáticas, tectônicas, geomorfológicas, hidrográficas, dentre outras, atuantes em épocas atuais e anteriores.

Como a região apresenta litologias variadas (granitos, efusivas ácidas a intermediárias, intrusivas básicas e rochas sedimentares arenosas), tais depósitos são constituídos principalmente por areias sílticas, siltes areno-argilosos e argilas silto-arenosas de cores avermelhadas, róseas, acastanhadas e acinzentadas. Devido aos fatores morfoclimáticos regionais, as espessuras desses depósitos são muito variáveis, chegando a atingir mais de 10 $\mathrm{m}$, em certos locais.

\section{MATERIAIS E MÉTODOS}

A radiação gama emitida pelo ${ }^{40} \mathrm{~K}$ e pelos radionuclídeos pertencentes às séries de decaimento do ${ }^{232} \mathrm{Th}$ e ${ }^{238} \mathrm{U}$ atravessa cerca de $30 \mathrm{~cm}$ de solos e de rochas (MINTY, 1997), de forma que a amostragem foi efetuada até uma profundidade de $25 \mathrm{~cm}$. Cada amostra, com cerca de 3 a $4 \mathrm{~kg}$, foi acondicionada em saco plástico, devidamente identificado por meio de numeração sequencial, grafada em etiquetas (interna e externa) com caneta de tinta indelével.

A amostragem estendeu-se por toda a área de ocorrência do Granito Serra do Carambeí, concentrando-se nos álcalifeldspato granitos (granitos alasquíticos), onde estão localizados os alvos radioanômalos pesquisados pela Comissão Nacional de Energia Nuclear - CNEN, no início da década de 1970. (PINTO-COELHO, 1986). Foram coletadas 17 amostras de rochas (sãs e intemperizadas) e 44 amostras de materiais do manto de intemperismo e de depósitos aluviais.

\subsection{Ensaios radioquímicos}

As concentrações dos radionuclídeos ${ }^{40} \mathrm{~K}$, ${ }^{232} \mathrm{Th}$ e ${ }^{238} \mathrm{U}$ foram determinadas por meio de análise por ativação neutrônica (AAN), importante ferramenta analítica para a determinação de elementos traço em diversas matrizes, sensível o suficiente para quantificar concentrações da ordem de ppm ou abaixo, bem como de elementos maiores. (IAEA, 2003b). Essa técnica está fundamentada nas reações que ocorrem no núcleo atômico quando irradiado com nêutrons, de forma que a quantificação da radioatividade induzida artificialmente pela irradiação de uma amostra permite a determinação da sua composição química.

Quando o interesse é analisar emissores gama como o ${ }^{40} \mathrm{~K}$ e nuclídeos radiogênicos das séries do ${ }^{238} \mathrm{U}$ e do ${ }^{232} \mathrm{Th}$ em questão, a radioatividade induzida é medida por meio de gamaespectrometria. (IAEA, 1990; IAEA, 2003b; MENEZES; JAĆIMOVIĆ, 2006). Esses ensaios foram realizados no Centro de Desenvolvimento da Tecnologia Nuclear/Comissão Nacional de Energia Nuclear (CDTN/CNEN) em reator TRIGA MARK I IPR-R1, com potência de 100 kW. As amostras foram irradiadas durante 8 horas com fluxo médio de neutros térmicos de $6,6 \times 10^{11} / \mathrm{cm}^{2}$ s.

A preparação das amostras constou de secagem a $50^{\circ} \mathrm{C}$ por 48 horas e posterior quarteamento até obtenção de alíquotas de 50 g cada. Essas foram moídas em moinho de bolas planetário com bojo de porcelana até passagem total em peneira de malha 200 (0,075 mm de abertura) (ABNT, 1988), sendo então enviadas para análise. A preparação foi realizada no Laboratório de Materiais Cerâmicos do Departamento de Engenharia de Materiais da Universidade Estadual de Ponta Grossa (UEPG). 


\subsection{Análises granulométricas}

Com o objetivo de identificar alguma relação entre tamanho de partícula e concentração de radionuclídeos, visto que cátions radioativos podem se fixar em minerais de argila (REBELLO, 2000; BECEGATO, 2005; BECEGATO; FERREIRA, 2005), 42 amostras provenientes do manto de alteração e de depósitos aluviais foram submetidas a ensaios granulométricos.

Para evitar alterações nas características granulométricas, de cada amostra natural, seca a $105^{\circ} \mathrm{C}$ durante 48 horas e não submetida a qualquer tratamento mecânico prévio, foram tomadas alíquotas de $100 \mathrm{~g}$. Cada alíquota, após adição de cerca de 500 $\mathrm{ml}$ de água destilada, foi submetida à desagregação em agitador mecânico durante 15 minutos, sendo a suspensão "água/material desagregado" peneirada a úmido em peneira de malha $80(0,18 \mathrm{~mm}$ de abertura) (ABNT, 1988) com recolhimento de toda a suspensão passante. $\mathrm{O}$ resíduo retido na peneira de malha $80(0,18 \mathrm{~mm})$, após secagem a $110^{\circ} \mathrm{C}$, foi separado em classes granulométricas por meio de peneiramento convencional a seco, enquanto cerca de $1 \mathrm{~g}$ da suspensão passante na peneira de malha 80 foi ensaiada em analisador de tamanho de partículas a laser - CILA 1064, com faixa analítica entre 0,04 e 500 $\mu \mathrm{m}$. Esses ensaios (análise granulométrica integrada) foram realizados no Laboratório de Análise de Minerais e Rochas - LAMIR/ UFPR.

\section{RESULTADOS E DISCUSSÕES}

As concentrações de ${ }^{232}$ Th e do ${ }^{238} \mathrm{U}$ obtidas nos ensaios radioquímicos, por terem sido expressas em $\mathrm{mg} / \mathrm{kg}$ (equivalentes a ppm - parte por milhão), não necessitaram de quaisquer transformações. Quanto ao ${ }^{40} \mathrm{~K}$, cujos resultados foram apresentados como atividade específica (Bq/ kg), a conversão para concentração foi efetuada considerando $313 \mathrm{~Bq} / \mathrm{kg}$ de ${ }^{40} \mathrm{~K}$ equivalentes a $1 \%$ de K. (IAEA, 2003a).

Em diversas amostras analisadas verificou-se concentração de ${ }^{238} \mathrm{U}$ inferior a 0,5 ppm $(<0,5$ ppm), o mesmo acontecendo com $\mathrm{O}^{40} \mathrm{~K}$, onde algumas amostras tiveram atividades específicas menores que $1,5 \mathrm{~Bq} /$ $\mathrm{kg}(<1,5 \mathrm{~Bq} / \mathrm{kg})$. Por não haver qualquer referência a respeito no presente estudo, tais valores foram admitidos como sendo concentrações e atividades específicas inferiores ao limite de detecção do método utilizado. Assim, considerando que é praticamente nula a probabilidade de que tais valores reduzam-se imediatamente do limite de detecção $(0,5$ ppm ou $1,5 \mathrm{~Bq} / \mathrm{kg})$ para zero, aos mesmos foram atribuídos, para efeitos de cálculo, valores equivalentes a $25 \%$ do limite de detecção. Dessa forma, às concentrações de ${ }^{238} \mathrm{U}$ referidas como $<0,5 \mathrm{mg} / \mathrm{kg}$ atribuiu-se o valor 0,125 ppm e, às atividades específicas de ${ }^{40} \mathrm{~K}$ indicadas como $<1,5 \mathrm{~Bq} / \mathrm{kg}$, atribuiu-se o valor $0,375 \mathrm{~Bq} / \mathrm{kg}$ (equivalente a 0,001\% de K) (Tabela 1).

Tabela 1 - Concentrações de $\mathrm{K}$, de ${ }^{232} \mathrm{Th}$ e de ${ }^{238} \mathrm{U}$ referentes aos ensaios radioquímicos realizados em amostras da área de estudo. Em destaque (negrito), concentrações e atividades específicas abaixo do limite de detecção do método utilizado

\begin{tabular}{c|c|c|c|c|c|c|c|c}
\hline Amostra & K (\%) & ${ }^{232} \mathrm{Th}(\mathrm{ppm})$ & ${ }^{238} \mathrm{U}(\mathrm{ppm})$ & & Amostra & $\mathrm{K}(\%)$ & ${ }^{232} \mathrm{Th}(\mathrm{ppm})$ & ${ }^{238} \mathrm{U}(\mathrm{ppm})$ \\
\hline AM-01 & 0,441 & 19,000 & 5,200 & & AM-26A & 3,760 & 26,000 & 3,700 \\
\hline AM-02 & 0,061 & 15,000 & 0,125 & & AM-27 & 0,001 & 14,000 & 3,100 \\
\hline AM-03 & 0,001 & 52,000 & 8,300 & & AM-28 & 0,001 & 18,000 & 4,000 \\
\hline AM-04 & 0,176 & 36,000 & 0,125 & & AM-29 & 0,054 & 10,300 & 3,100 \\
\hline AM-05 & 0,051 & 24,000 & 0,125 & & AM-30 & 0,300 & 19,000 & 3,200 \\
\hline AM-06 & 0,070 & 21,000 & 9,800 & & AM-31 & 0,281 & 27,000 & 3,500 \\
\hline AM-06A & 5,099 & 19,000 & 4,600 & & AM-32 & 0,230 & 22,000 & 3,000 \\
\hline
\end{tabular}


conclusão

\begin{tabular}{|c|c|c|c|c|c|c|c|}
\hline AM-07 & 0,243 & 25,000 & 0,125 & AM-33 & 0,508 & 4,700 & 0,125 \\
\hline AM-07A & 0,470 & 26,000 & 5,300 & AM-34 & 3,399 & 37,000 & 8,000 \\
\hline AM-08 & 3,524 & 39,000 & 9,200 & AM-35 & 0,460 & 24,000 & 3,800 \\
\hline AM-09 & 0,441 & 45,000 & 7,400 & AM-36 & 0,173 & 29,000 & 4,900 \\
\hline AM-10 & 0,089 & 48,000 & 2,500 & AM-37 & 0,304 & 23,000 & 3,700 \\
\hline AM-11 & 0,005 & 7,400 & 0,125 & AM-38 & 0,128 & 26,000 & 5,400 \\
\hline AM-12 & 3,933 & 25,000 & 7,000 & AM-39 & 3,805 & 33,000 & 0,125 \\
\hline AM-13 & 0,077 & 31,000 & 0,125 & AM-40 & 3,994 & 33,000 & 4,600 \\
\hline AM-14 & 0,064 & 38,000 & 0,125 & AM-41 & 3,524 & 39,000 & 9,100 \\
\hline AM-15 & 0,054 & 42,000 & 0,125 & $\mathrm{AM}-41 \mathrm{~A}$ & 0,163 & 1,100 & 0,125 \\
\hline AM-16 & 0,141 & 85,000 & 12,000 & AM-42 & 0,188 & 85,000 & 9,100 \\
\hline AM-17 & 0,001 & 23,000 & 0,125 & AM-43 & 0,099 & 49,000 & 7,600 \\
\hline AM-18 & 0,048 & 27,000 & 0,125 & AM-44 & 0,080 & 1,800 & 0,400 \\
\hline AM-19 & 3,661 & 21,000 & 15,000 & AM-45 & 0,233 & 30,000 & 5,300 \\
\hline AM-19A & 3,786 & 16,000 & 5,500 & AM-46 & 2,310 & 16,000 & 3,100 \\
\hline AM-19B & 3,588 & 48,000 & 5,100 & AM-47 & 0,144 & 18,000 & 5,000 \\
\hline AM-20 & 0,217 & 32,000 & 5,400 & AM-48 & 4,524 & 36,000 & 6,300 \\
\hline AM-21 & 0,163 & 32,000 & 5,100 & AM-49 & 0,393 & 22,000 & 3,700 \\
\hline AM-22 & 0,070 & 37,000 & 5,500 & AM-50 & 3,479 & 20,000 & 5,000 \\
\hline AM-23 & 0,070 & 29,000 & 9,700 & AM-51 & 0,153 & 24,000 & 4,200 \\
\hline AM-24 & 0,211 & 36,000 & 5,400 & AM-52 & 0,137 & 47,000 & 4,300 \\
\hline AM-25 & 0,058 & 45,000 & 6,600 & AM-53 & 0,581 & 24,000 & 5,200 \\
\hline AM-25A & 0,038 & 40,000 & 5,000 & AM-55 & 2,895 & 29,000 & 5,600 \\
\hline AM-26 & 0,073 & 29,000 & 6,300 & & & & \\
\hline
\end{tabular}

Fonte: Ensaios em laboratório das amostras coletadas em campo, 2009

Para uma melhor visualização da forma como os radionuclídeos estão distribuídos na área procedeu-se o agrupamento dos mesmos em intervalos de classes com base no critério de Sturges (MARANHÃO, 1985; GUERRA, 1988), representado pela equação (1):

$\mathrm{It}=\mathrm{A} 1+3,322 \times \log \mathrm{N}(1)$
Onde: It é o intervalo de classe; A corresponde à amplitude; $\mathrm{N}$ corresponde ao número de observações (amostras).

De acordo com esse critério, os dados referentes às 61 amostras foram agrupados em sete classes de distribuição de frequência, conforme exposto na Tabela 2 e ilustrado na Figura 3.

Tabela 2 - Distribuição de frequência das concentrações de radionuclídeos referentes aos ensaios radioquímicos de amostras da área de estudo

\begin{tabular}{c|c|c|c|c|c|c}
\hline & \multicolumn{2}{|c|}{$\mathrm{K}(\%)$} & \multicolumn{2}{c}{${ }^{238} \mathrm{U}$} & \multicolumn{2}{c}{${ }^{232} \mathrm{Th}$} \\
\hline Classes & Conc. (\%) & Freq. & Conc. (ppm) & Freq. & Conc. (ppm) & Freq. \\
\hline 1 & $0,001-0,73$ & 46 & $0,13-2,26$ & 14 & $1,10-13,09$ & 5 \\
\hline 2 & $0,73-1,46$ & 0 & $2,26-4,38$ & 14 & $13,09-25,07$ & 22 \\
\hline 3 & $1,46-2,19$ & 0 & $4,38-6,50$ & 20 & $25,07-37,06$ & 20 \\
\hline 4 & $2,19-2,91$ & 2 & $6,50-8,63$ & 6 & $37,06-49,04$ & 11 \\
\hline 5 & $2,91-3,64$ & 5 & $8,63-10,76$ & 5 & $49,04-61,03$ & 1 \\
\hline 6 & $3,64-4,37$ & 6 & $10,76-12,88$ & 1 & $61,03-73,01$ & 0 \\
\hline 7 & $4,37-5,10$ & 2 & $12,88-15,00$ & 1 & $73,01-85,00$ & 2 \\
\hline Total de ensaios & & 61 & & 61 & & 61 \\
\hline
\end{tabular}


conclusão

\begin{tabular}{c|c|c|c|c|c|c|c}
\hline \multirow{2}{*}{ Concentrações } & Máxima & 5,10 & 15,00 & 85,00 & 29,51 \\
\cline { 2 - 7 } & Média & 1,04 & & 4,52 & 1,10 & 15,50 \\
\cline { 2 - 7 } & Mínima & 0,001 & & 0,13 & & 52,52 \\
\hline
\end{tabular}

Org: GODOY (2010)

Tabela 3 - Classes de distribuição dos radionuclídeos da área de estudo em função de sua regularidade

\begin{tabular}{c|c}
\hline, & Coeficiente de dispersão (\%) \\
\hline Regular & $5-40$ \\
\hline Irregular & $40-100$ \\
\hline Muito irregular & $100-150$ \\
\hline Extremamente irregular & $>150$ \\
\hline
\end{tabular}

Fonte: Adaptado de MARANHÃO, 1985.

\subsection{Potássio (K)}

As concentrações de K (\%) obtidas nas 61 amostras coletadas na área de estudo variaram de $0,001 \%$ a 5,10\%, com média de $1,04 \%$, sendo que valores inferiores a $0,73 \%$ são predominantes, ocorrendo em 46 pontos de amostragem $(75,4 \%$ das amostras) (Tabela 2; Figura 4A).

Com coeficiente de dispersão de $150,60 \%$ para as 61 amostras analisadas, o potássio caracteriza-se por uma distribuição extremamente irregular, conforme a classificação proposta por Maranhão (1985) (Tabela 3). A análise dos dados agrupados por litotipos (Tabela 4) revelou que a maior heterogeneidade de distri-
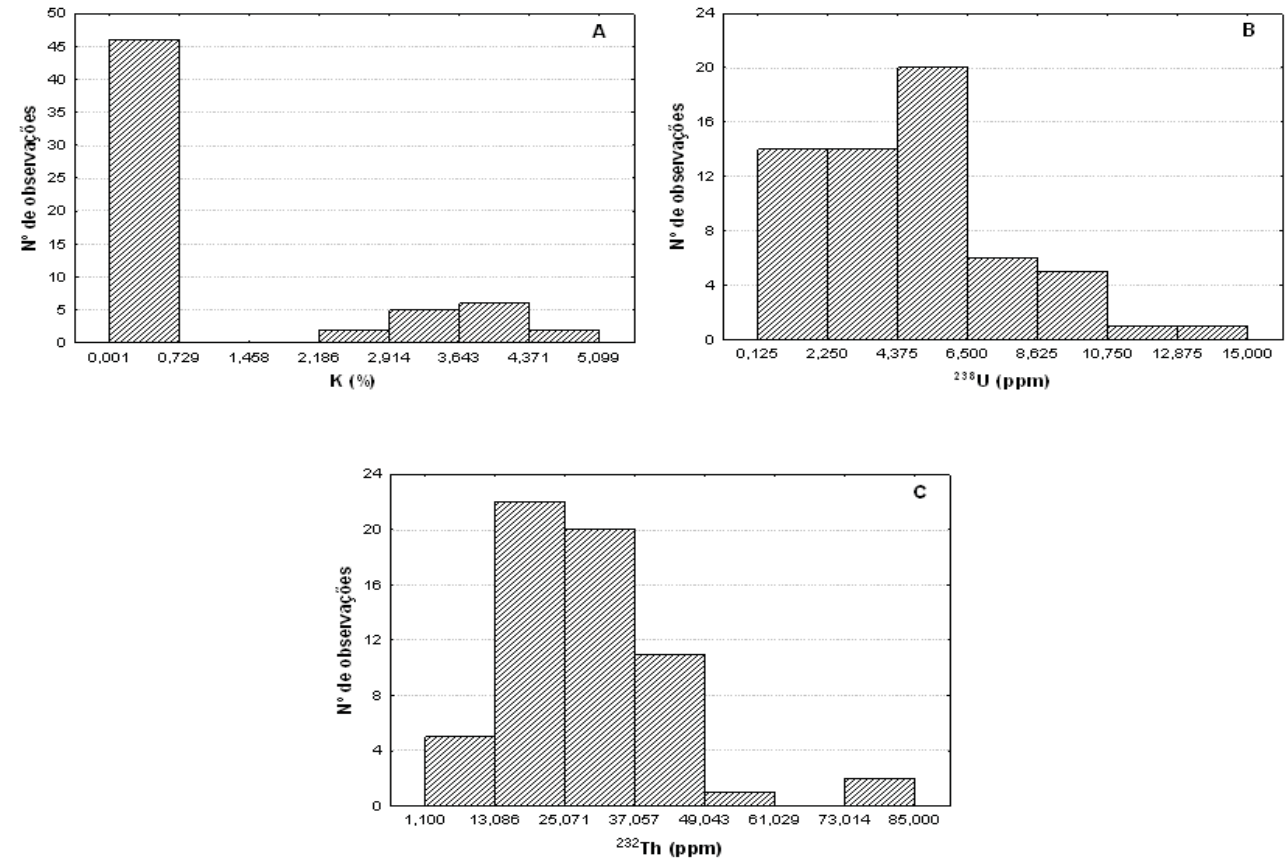

Figura 3 - Histogramas com as distribuições de frequências das concentrações de K (A), ${ }^{238} \mathrm{U}(\mathrm{B})$ e ${ }^{232} \mathrm{Th}(\mathrm{C})$, referentes aos ensaios radioquímicos de amostras da área de estudo

Org: GODOY, 2010 
Tabela 4 - Parâmetros estatísticos $\left(\mathrm{K},{ }^{238} \mathrm{U},{ }^{232} \mathrm{Th}\right)$ referentes aos dados radioquímicos nos diversos litotipos ocorrentes na área de estudo

\begin{tabular}{|c|c|c|c|c|}
\hline $\begin{array}{c}\text { Unidade lítica } \\
\text { (Nº observações) }\end{array}$ & Parâmetros estatísticos & K (\%) & ${ }^{238} \mathrm{U}(\mathrm{ppm})$ & ${ }^{232} \mathrm{Th}$ (ppm) \\
\hline \multirow{5}{*}{$\begin{array}{l}\text { Aluviões } \\
\text { (2) }\end{array}$} & Concentração máxima & 2,31 & 3,80 & 24,00 \\
\hline & Concentração média & 1,39 & 3,45 & 20,00 \\
\hline & Concentração mínima & 0,46 & 3,10 & 16,00 \\
\hline & Desvio padrão & 1,31 & 0,49 & 5,66 \\
\hline & Coeficiente dispersão (\%) & 94,44 & 14,35 & 28,28 \\
\hline \multirow{5}{*}{$\begin{array}{c}\text { CGC - GSC Álcali-fedspato granitos } \\
\qquad(46)\end{array}$} & Concentração máxima & 5,10 & 15,00 & 85,00 \\
\hline & Concentração média & 1,26 & 4,90 & 32,99 \\
\hline & Concentração mínima & 0,001 & 0,13 & 1,10 \\
\hline & Desvio padrão & 1,72 & 3,60 & 16,05 \\
\hline & Coeficiente dispersão (\%) & 136,65 & 73,39 & 48,66 \\
\hline \multirow{5}{*}{$\begin{array}{l}\text { CGC - GSC Fácies de borda } \\
\qquad(12)\end{array}$} & Concentração máxima & 0,51 & 5,00 & 29,00 \\
\hline & Concentração média & 0,18 & 3,16 & 18,67 \\
\hline & Concentração mínima & 0,001 & 0,13 & 4,70 \\
\hline & Desvio padrão & 0,15 & 1,57 & 6,98 \\
\hline & Coeficiente dispersão (\%) & 81,18 & 49,60 & 37,39 \\
\hline $\begin{array}{l}\text { CGC - Domínio Jotuba-Pitangui } \\
\text { (1) }\end{array}$ & Concentração & 0,441 & 5,20 & 19,00 \\
\hline
\end{tabular}

Org: GODOY, 2010

Do que se observa no mapa de contorno de potássio, os maiores teores deste elemento estão localizados principalmente em meias-encostas e em fundos de vale, sugerindo que o mesmo, por ser muito reativo, é intensamente lixiviado do manto de intemperismo que capeia os topos de morros. Indica ainda remoção mecânica (erosiva) de parte do perfil de alteração que capeia as encostas, já depletado em $\mathrm{K}$, devido à maior suscetibilidade aos processos erosivos verificada nestes locais de declividade mais acentuada, o que leva à exposição do substrato rochoso e/ ou de rochas menos afetadas por processos intempéricos. Assim, o material intemperizado, removido das regiões mais elevadas, seria temporariamente acumulado nas porções mais inferiores das encostas, bem como nos fundos de vales das proximidades das regiões erodidas (área fonte), provável razão das maiores concentrações de $\mathrm{K}$ serem encontradas nestes compartimentos geomorfológicos.

\subsection{Urânio $\left({ }^{238} \mathrm{U}\right)$}

$\mathrm{Na}$ área, o urânio se encontra em concentrações que variam de 0,13 ppm a 15,00 ppm e média de 4,52 ppm, ou seja, cerca de duas vezes superior à abundância média da crosta terrestre (Tabela 2). Apesar de irregularmente distribuído (coeficiente de dispersão de 72,37\%), o mapa de contorno de urânio (Figura 4B) evidencia a existência de algumas zonas enriquecidas em ${ }^{238} \mathrm{U}$, principalmente nas regiões centro-leste, centro-oeste, nordeste e sul dos álcalifeldspato granitos.

O agrupamento dos dados por litotipos também mostra maiores concentrações de urânio, preferencialmente, nos álcalifeldspato granitos (Tabela 4) que, com 46 amostras analisadas, apresentou um teor médio de 4,90 ppm e concentrações absolutas oscilando entre 0,13 ppm e 15,00 ppm, confirmando o caráter radioanômalo dessas rochas. 
As menores concentrações de ${ }^{238} \mathrm{U}$ foram encontradas na fácies de borda, onde a média, em 12 amostras analisadas, foi de 3,16 ppm e teores absolutos entre 0,13 ppm e 5,00 ppm.

De acordo com o mapa de contorno de urânio sobreposto ao modelo digital de elevação, os maiores teores de ${ }^{238} \mathrm{U}$ estão situados dominantemente nos terços superior e médio de vertentes, provavelmente devido à menor espessura do manto de alteração, bem como pela lixiviação parcial do urânio contido na matriz lítica em processos de decomposição. A partir dessa porção do relevo em direção às regiões de cotas mais elevadas (topos de morros situados em maiores altitudes), verifica-se uma redução gradativa nos teores de urânio, a qual pode estar relacionada à menor declividade desses locais que, favorecendo a percolação de águas pluviais, intensifica a lixiviação desse elemento, cuja mobilidade é elevada, principalmente em ambiente oxidante. Da mesma forma, a partir do terço médio das vertentes em direção aos fundos de vales, verifica-se novamente uma redução gradativa dos teores de urânio relacionada, provavelmente, ao acúmulo de materiais do manto de alteração removidos das porções mais superiores, cujo urânio já teria sido parcialmente lixiviado.

\subsection{Tório $\left({ }^{232} \mathrm{Th}\right)$}

O tório é o radioisótopo mais abundante na área de pesquisa, com concentrações variando de 1,10 ppm a 85,00 ppm e média de 29,51 ppm nas 61 amostras. Concentrações superiores à média da crosta terrestre são predominantes, ocorrendo em 56 amostras $(91,80 \%)$, conforme a Tabela 4 . É o radionuclídeo com distribuição mais regular na área de estudo, com coeficiente de dispersão de $52,52 \%$.
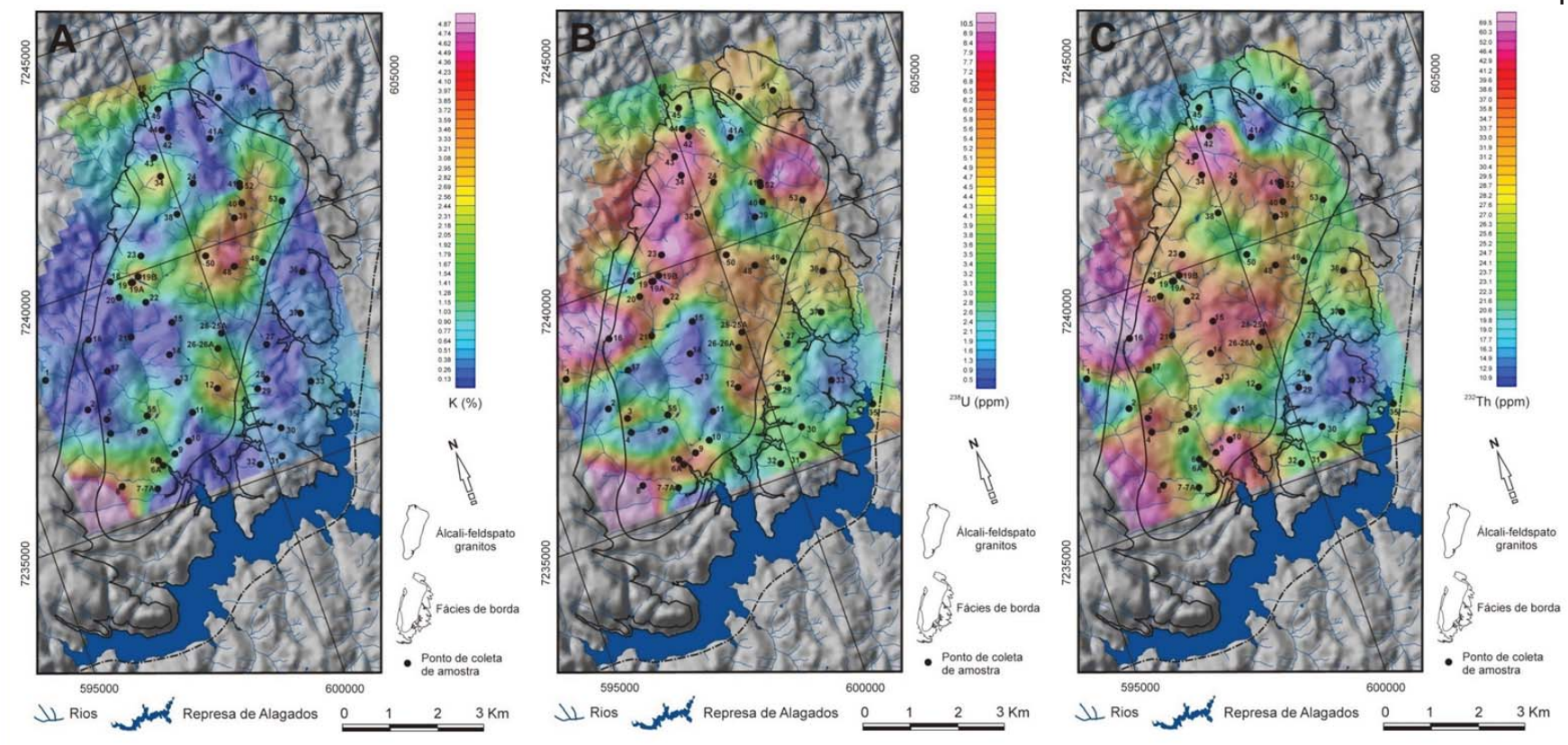

Figura 4 - Mapas de contorno de K (A), ${ }^{238} \mathrm{U}$ (B) e ${ }^{232} \mathrm{Th}(\mathrm{C})$ sobrepostos ao modelo digital de elevação Org: GODOY, 2010 
As maiores concentrações deste radioisótopo são encontradas nos álcalifeldspato granitos, cujos valores absolutos, em 46 amostras, variaram de 1,10 ppm a 85,00 ppm, com média de 32,99 ppm e coeficiente de dispersão de 48,66\% (Tabela 4). Considerando, no entanto, que os menores teores (AM 41A - 1,10 ppm e AM 44 -1,80 ppm) referem-se a amostras de veios de quartzo de ocorrência muito restrita, as concentrações de tório nas 44 amostras representativas dos álcali-feldspato granitos e respectivos produtos de alteração estariam situadas entre $7,40 \mathrm{ppm}$ e 85 ppm, média de 34,42 ppm e coeficiente de dispersão de 43,21\%. Dessas, 43 amostras $(97,7 \%)$ tiveram teores de tório superiores a 16,00 ppm.

$\mathrm{Na}$ fácies de borda, onde foram coletadas 12 amostras, as concentrações são significativamente menores, oscilando entre 4,70 ppm e 29,00 ppm, com média de 18,67 ppm.

O mapa de contorno de tório sobreposto ao modelo digital de elevação (Figura 4C) mostra certa regularidade na distribuição do ${ }^{232}$ Th. Mesmo assim, é possível delimitar algumas zonas que concentram altos teores, situadas nas porções sul, central e norte dos álcali-feldspato granitos. Verifica-se, ainda, que os maiores teores são encontrados, preferencialmente, em topos de morros e nas porções mais elevadas de cabeceiras de drenagens (terço superior e médio das vertentes), onde os fluxos de superfície, em condições normais de precipitação, não teriam energia suficiente para iniciar grandes processos erosivos que pudessem promover a mobilização mecânica do tório liberado da rocha matriz. Dessa forma, a baixa mobilidade desse radioisótopo dificultaria a lixiviação do mesmo pelas águas meteóricas que percolam o manto de alteração, possibilitando a incorporação e concentração do ${ }^{232} \mathrm{Th}$ no capeamento intempérico desse compartimento geomórfico.

\subsection{Análises granulométricas}

As coberturas cenozóicas da área são constituídas por materiais com granulometrias variáveis, em que as partículas mais grossas (grânulo/areia) são predominantes em 20 das 42 amostras analisadas. $\mathrm{Na}$ sequência tem-se o intervalo silte, predominante em 18 amostras, e a granulação argila que ocorre em maiores percentuais em apenas quatro amostras (Tabela 5). Assim, a plotagem dos dados granulométricos no diagrama triangular para classificação de depósitos sedimentares recentes (Figura 5) mostra que os capeamentos intempéricos e os depósitos aluviais em estudo são constituídos por areia síltica (17 amostras), silte areno-argiloso (8), silte argiloso (6), silte arenoso (4), areia silto-argilosa (3), argila silto-arenosa (3) e argila síltica (1).

Apesar de a fração grânulo/areia predominar no maior número de amostras - e pelo fato de terem sido analisadas alíquotas de 100 g de cada uma delas - o intervalo granulométrico mais representativo dos materiais inconsolidados da área é o silte, com média de $39,11 \%$ em peso, equivalentes a uma média de 39,11 g de silte por amostra (Tabela 5). O coeficiente de dispersão de $19,88 \%$ indica que partículas na granulação silte encontram-se distribuídas regularmente na área pesquisada, com valores absolutos situados entre 18,27\% e 55,08\% em peso. Quanto ao intervalo grânulo/areia, com valores absolutos entre $3,08 \%$ e $74,37 \%$ em peso e média de $37,57 \%$ em peso, a distribuição é irregular $(\mathrm{Cd}=43,02 \%)$. A granulação argila é a que ocorre em menor quantidade, com média de $23,36 \%$ em peso (média de 23,36 g por amostra) e valores absolutos entre 7,36\% e $47,30 \%$ em peso. Com coeficiente de dispersão de $49,94 \%$, é a classe granulométrica de distribuição mais irregular na área pesquisada.

A análise e interpretação do comportamento dos radionuclídeos $\mathrm{K},{ }^{238} \mathrm{U}$ e 
${ }^{232}$ Th em função dos diferentes intervalos granulométricos foi efetuada com base na matriz de correlação de Pearson. Porém, considerando que depósitos inconsolidados (manto de intemperismo e depósitos aluviais) em geral encontram-se parcialmente exauridos em potássio devido à sua alta mobilidade e à permeabilidade elevada desses depósitos, na elaboração da matriz de correlação (Tabela 6) foram suprimidos os maiores teores desse elemento, referentes às amostras AM 08, com 3,52\% de K e AM 46, com 2,31\%.

Portanto, o coeficiente de correlação negativo $(-0,34)$ entre o $\mathrm{K}$ e partículas na fração grânulo/areia estaria relacionado à natureza desses materiais (principalmente quartzosos) e à maior permeabilidade dos mesmos, que favoreceria a percolação de água e, em consequência, a lixiviação de grande parte do potássio contido nesses materiais.

O coeficiente de correlação positivo $(0,43)$ entre o Ke a fração argila (Tabela 6) é indicativo de que parte do potássio estaria incorporada à estrutura de argilominerais (provavelmente ilita), podendo ainda estar relacionado à presença de feldspato potássico finamente divididos, em vias de decomposição.

Tabela 5 - Composição granulométrica percentual de amostras coletadas no manto de alteração e em depósitos aluviais da área de estudo

\begin{tabular}{c|c|c|c}
\hline Amostra & Areia/grânulo & Silte & Argila \\
\hline AM 01 & 30,86 & 39,45 & 29,70 \\
\hline AM 02 & 60,05 & 30,90 & 9,06 \\
\hline AM 03 & 42,19 & 45,16 & 12,65 \\
\hline AM 04 & 48,36 & 37,60 & 14,04 \\
\hline AM 05 & 34,35 & 46,03 & 19,62 \\
\hline AM 06 & 30,68 & 42,70 & 26,62 \\
\hline AM 07 & 43,42 & 43,43 & 13,15 \\
\hline AM 07A & 17,94 & 52,01 & 30,05 \\
\hline AM 08 & 55,22 & 33,99 & 10,79 \\
\hline AM 09 & 52,38 & 30,99 & 16,63 \\
\hline AM 10 & 44,18 & 42,30 & 13,52 \\
\hline
\end{tabular}

\begin{tabular}{|c|c|c|c|}
\hline AM 11 & 49,84 & 36,93 & 13,23 \\
\hline AM 13 & 45,49 & 40,63 & 13,88 \\
\hline AM 14 & 50,00 & 28,50 & 21,50 \\
\hline AM 15 & 46,04 & 32,95 & 21,01 \\
\hline AM 16 & 24,09 & 39,01 & 36,90 \\
\hline AM 18 & 58,23 & 26,06 & 15,72 \\
\hline AM 20 & 50,04 & 38,18 & 11,79 \\
\hline AM 21 & 44,54 & 30,39 & 25,07 \\
\hline AM 22 & 41,91 & 44,75 & 13,33 \\
\hline AM 24 & 47,35 & 41,22 & 11,43 \\
\hline AM 25 & 44,85 & 37,78 & 17,37 \\
\hline AM 25A & 52,73 & 34,23 & 13,04 \\
\hline AM 27 & 30,05 & 48,43 & 21,52 \\
\hline AM 28 & 26,21 & 39,17 & 34,61 \\
\hline AM 29 & 13,78 & 43,00 & 43,22 \\
\hline AM 30 & 27,51 & 32,43 & 40,07 \\
\hline AM 31 & 29,17 & 34,07 & 36,76 \\
\hline AM 32 & 18,72 & 42,51 & 38,77 \\
\hline AM 33 & 3,08 & 49,62 & 47,30 \\
\hline AM 35 & 6,50 & 46,70 & 46,80 \\
\hline AM 36 & 27,41 & 42,06 & 30,53 \\
\hline AM 37 & 27,67 & 40,35 & 31,98 \\
\hline AM 38 & 30,33 & 50,35 & 19,32 \\
\hline AM 43 & 53,27 & 34,95 & 11,79 \\
\hline AM 45 & 23,49 & 44,39 & 32,12 \\
\hline AM 46 & 59,98 & 28,52 & 11,50 \\
\hline AM 47 & 19,75 & 55,08 & 25,17 \\
\hline AM 49 & 20,15 & 35,15 & 44,71 \\
\hline AM 51 & 16,61 & 51,25 & 32,14 \\
\hline AM 52 & 74,37 & 18,27 & 7,36 \\
\hline AM 53 & 53,40 & 31,35 & 15,25 \\
\hline Máximo & 74,37 & 55,08 & 47,30 \\
\hline Média & 37,53 & 39,11 & 23,36 \\
\hline Mínimo & 3,08 & 18,27 & 7,36 \\
\hline $\begin{array}{l}\text { Desvio } \\
\text { padrão }\end{array}$ & 16,15 & 7,78 & 11,67 \\
\hline $\begin{array}{c}\text { Coef. } \\
\text { dispersão }\end{array}$ & 43,02 & 19,88 & 49,94 \\
\hline
\end{tabular}

Fonte: Ensaios em laboratório das amostras coletadas em campo, 2009 


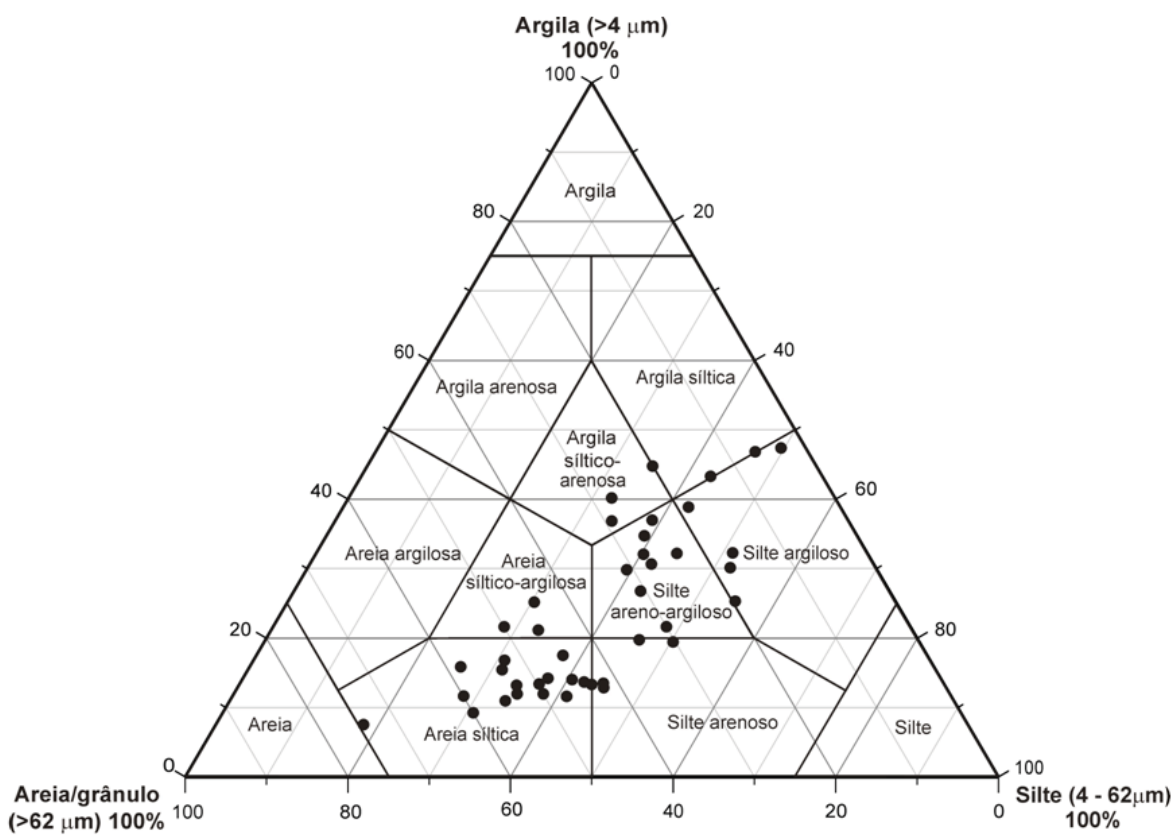

Figura 5 - Diagrama triangular com a classificação dos materiais do manto de alteração e de depósitos aluviais da área de estudo Fonte: MENDES et al., 1972

Tabela 6 - Matriz de correlação de Pearson para os dados de ensaios granulométricos e radioquímicos de amostras coletadas na área de estudo. Em destaque, correlações significativas com limite de confiança de $95 \%$

\begin{tabular}{c|c|c|c|c|c|c}
\hline & $\mathrm{K}$ & ${ }^{238} \mathrm{U}$ & ${ }^{232} \mathrm{Th}$ & $\begin{array}{c}\text { Grânulo/ } \\
\text { Areia }\end{array}$ & Silte & Argila \\
\hline $\mathrm{K}$ & 1,00 & & & & & \\
\hline${ }^{238} \mathrm{U}$ & 0,08 & 1,00 & & & & \\
\hline${ }^{232} \mathrm{Th}$ & $-0,19$ & 0,52 & 1,00 & & & \\
\hline Areia/Grânulo & $-0,34$ & $-0,11$ & 0,37 & 1,00 & & \\
\hline Silte & 0,06 & 0,12 & $-0,28$ & $-0,72$ & 1,00 & \\
\hline Argila & 0,43 & 0,07 & $-0,32$ & $-0,89$ & 0,32 & 1,00 \\
\hline
\end{tabular}

Org: GODOY, 2010

No caso do tório, o coeficiente de correlação positivo $(0,37)$ com materiais sedimentares grossos (grânulo/areia) permite supor que esse radionuclídeo ocorra como espécie mineral (resistato) e/ou combinado a silicatos (zircão?). Os coeficientes de correlação negativos entre tório e a classe silte $(-0,28)$ e entre tório e argila $(-0,32)$ também são indicativos da presença do tório como espécie mineral ou combinado a silicatos, haja vista a tendência de aumen- to nas concentrações de ${ }^{232} \mathrm{Th}$ à medida que diminuem as percentagens de silte e de argila e, em consequência, aumenta a quantidade de partículas mais grossas.

As fracas correlações entre ${ }^{238} \mathrm{U}$ e os diversos intervalos granulométricos que compõem os depósitos inconsolidados da área não permitiram estabelecer vinculação entre os mesmos.

\section{CONSIDERAÇÕES FINAIS}

De acordo com dados radioquímicos de amostras coletadas na área de estudo, os radionuclídeos naturais ${ }^{40} \mathrm{~K},{ }^{238} \mathrm{U}$ e ${ }^{232} \mathrm{Th}$ estão distribuídos de forma irregular, inversamente proporcional às respectivas concentrações. Assim, o tório, que ocorre em maiores concentrações, é o radionuclídeo mais bem distribuído na área, enquanto o potássio, que teve as menores concentrações, é o que apresenta distribuição mais irregular.

Apesar de irregularmente dispersos, concentrações mais elevadas, sobretudo de urânio e de tório, são observadas principalmente na área de ocorrência dos álcali-feldspato granitos, corpo central do Granito Serra do Carambeí, confirmando as características radioanômalas dessas rochas.

Os mapas de contorno mostraram que teores mais elevados de potássio são encontrados principalmente em meias-encostas e em fundos de vale, sugerindo intensa lixiviação dese elemento nos topos de morros, enquanto o urânio se concentra, sobretudo, nos terços superior e médio de vertentes, 
indicando que a redução das concentrações em regiões mais elevadas (topos de morros) estaria relacionada à maior lixiviação desse radioisótopo altamente móvel. Da mesma forma, maiores concentrações de tório são encontradas em topos de morros e nas porções mais elevadas de cabeceiras de drenagens, provavelmente devido à sua baixa mobilidade.

Quanto ao comportamento dos radionuclídeos em materiais de diferentes granulometrias, verificou-se que apenas o potássio e o tório permitiram estabelecer alguma correlação, com tendência de baixos teores de potássio em materiais de granulação grossa e de aumento dos teores em materiais mais argilosos, não se descartando a possibilidade de que parte do potássio esteja incorporada à ilita. O inverso ocorre com o tório, cujos maiores teores são verificados em materiais sedimentares grossos (grânulo/areia), indicando a possibilidade de que ${ }^{232} \mathrm{Th}$ ocorra como espécie mineral (resistato) e/ou combinado a silicatos.

\section{AGRADECIMENTOS}

Os autores agradecem a Luis Gustavo de Castro pela orientação no uso do aplicativo Geosoft OASIS Montaj. F.J.F. Ferreira e L.J.C. Santos agradecem ao CNPq pelas respectivas bolsas de produtividade em pesquisa.

\section{REFERÊNCIAS}

ASSINE, M. L. Aspectos da estratigrafia das seqüências précarboníferas da Bacia do Paraná no Brasil. 1996. Tese (Doutorado em Geologia Sedimentar) Instituto de Geociências, Universidade de São Paulo - USP. São Paulo. 207 p.

ASSOCIAÇÃO BRASILEIRA DE NORMAS TÉCNICAS - ABNT. NBR 5734: peneiras para ensaio, com telas de tecido metálico. Rio de Janeiro, 1988.
ATSDR - Agency for Toxic Substances and Disease Registry. Toxicological profile for ionizing radiation. Atlanta, 1999. 395 p.

BECEGATO, V. A. Aplicação de técnicas geofísicas e geoquímicas em duas glebas agrícolas do noroeste do Estado do Paraná e suas relações com fertilizantes fosfatados. 2005. Tese (Doutorado em Geologia Ambiental) Universidade Federal do Paraná - UFPR, Curitiba. 198 p.

BECEGATO, V. A.; FERREIRA, F. J. F. Gamaespectrometria, resistividade elétrica e susceptibilidade magnética de solos agrícolas no noroeste do Estado do Paraná. Revista Brasileira de Geofísica, v. 23, n. 4, p. 371-405, 2005.

BERGAMASCHI, S. Análise estratigráfica do siluro-devoniano (formações Furnas e Ponta Grossa) da sub-bacia de Apucarana, Bacia do Paraná, Brasil. 1999. Tese (Doutorado em Geologia Sedimentar) Instituto de Geociências, Universidade de São Paulo - USP. São Paulo. 167 p.

BONOTTO, D. M. Radioatividade nas águas: da Inglaterra ao Guarani. São Paulo: Editora UNESP, 2004.

DICKSON, B. L.; SCOTT, K. M. Interpretation of aerial gamma-ray surveys - adding the geochemical factors. AGSO Journal of Australian Geology \& Geophysics. Austrália, v. 17, n. 2, p. 187-200, 1997.

FERREIRA, F. J. F.; FORNAZZARI NETO, L.; GUIMARÃES, G. B.; ULBRICH, H. H. G. J. Contrastes gamaespectrométricos (K,eTh,eU) dos complexos graníticos Cunhaporanga e Três Córregos - PR: análise dos dados do BARMP (Brazil Airborne Radiometric Mapping Project). In: CONGRESSO BRASILEIRO DE GEOQUÍMICA, 10, e SIMPÓSIO DE GEOQUÍMICA DOS PAÍSES DO MERCOSUL, 2, 2005, Porto de Galinhas. Anais... São Paulo: SBGq, 2005.

FERREIRA, F. J. F.; RIFFEL, S. B.; FORLIN, M.; GUIMARÃES, G. B. Gamaespectrometria do Granito Serra do Carambeí-PR. In: CONGRESSO INTERNACIONAL DA SOCIEDADE BRASILEIRA DE GEOFÍSICA, 7, 2001, Salvador. Anais... Salvador: SBGf, 2001.

GUERRA, P. A. G. Geoestatística operacional. Brasília: Departamento Nacional de Produção Mineral, 1988. 145 p.

GUIMARÃES, G. B. As rochas granitóides do complexo granítico Cunhaporanga, Paraná: aspectos geológicos, geofísicos, geoquímicos 
e mineralógicos. 2000. Tese (Doutorado em Geociência) - Instituto de Geociências, Universidade de São Paulo - USP. São Paulo. 230 p.

GUIMARÃES, G. B.; FERREIRA, F. J. F.; ULBRICH, H. H. G. J.; FORLIN, M., The Aerogeophysical Project Serra do Mar Sul in the region of the Cunhaporanga Granitic Complex, Paraná, Southern Brazil: analysis of the gamma-ray spectrometric survey. Revista Brasileira de Geofísica, v. 19, n. 1, p. 3-18, 2001.

IAEA - International Atomic Energy Agency. Practical aspects of operating a neutron activation analysis laboratory. Vienna: IAEA-TECDOC-564, 1990. $250 \mathrm{p}$.

Guidelines for radioelement mapping using gamma ray spectrometry data. Vienna: IAEA-TECDOC-1363, 2003a. 173 p.

. Nuclear analytical techniques in archaeological investigations. Vienna: IAEA-TECREP-416, 2003b. 192 p.

MARANHÃO, R. J. L. Introdução à pesquisa mineral. Fortaleza: BNB, ETENE, 3. ed., 1985. 752 p.

MENDES, J. C.; BIGARELLA, J. J.; SALAMUNI, R. Estratigrafia e sedimentologia. Brasília: Instituto Nacional do Livro - MEC, p. 1-91, 1972.

MENEZES, M. A. B. C.; JAĆIMOVIĆ. R. Optimised $\mathrm{k}_{0}$-instrumental neutron activation method using the TRIGA MARK I IPR-R1 reactor at CDTN/ CNEN, Belo Horizonte, Brazil. Nuclear Instruments and Methods in Physics Research A, v. 564, n. 2, p. 707-715, 2006.

MILANI, E. J.; MELO, J. H. G. de; SOUZA, P. A. de.; FERNANDES, L. A.; FRANÇA, A. B. Bacia do Paraná. In: Cartas Estratigráficas. Boletim de Geociências da Petrobrás v. 15. n. 2, p. 265-287, 2007.

MINEROPAR - Minerais do Paraná S.A. Folha Ponta Grossa - Escala 1:250.000. 2. ed. Software de Geoprocessamento: ArcView 3. 2006a.

.Folha Telêmaco Borba - Escala 1:250.000. 2. ed. Software de Geoprocessamento: ArcView 3. $2006 \mathrm{~b}$.

MINTY, B. R. S. Fundamentals of airborne gammaray spectrometry. AGSO Journal of Australian Geology \& Geophysics. v. 17, n. 2, p. 39-50, 1997.

NCRP. 1987. Ionizing radiation exposure of the population of the United States. National Council on Radiation Protection and Measurements. NCRP Report n. 93, 69p

PINTO-COELHO, C. V. O granito Serra do Carambeí - PR e as anomalias uraníferas associadas.
1986. Tese de Mestrado, Departamento de Geociências, Universidade de Brasília - UnB. Brasília. $309 \mathrm{p}$.

. Petrografia e petroquímica do Granito Serra do Carambeí - Paraná. In: SIMPÓSIO SUL-BRSILEIRO DE GEOLOGIA, 3., 1987, Curitiba. Atas... Curitiba: SBGeo/Núcleo Paraná, Santa Catarina e Rio Grande do Sul, p. 551-570, 1987.

PINTO-COELHO, C. V.; SIEDLECKI, K. N. Distribuição de elementos radioativos no Granito Serra do Carambeí, Paraná, Brasil. Revista Brasileira de Geociências, v. 18, n. 4, p. 433-440, 1988.

REBELO, A. M. A. Processos supergênicos na distribuição de radônio em paisagens tropicais úmidas. 2000. Tese de Doutorado, Departamento de Geologia, Setor de Ciências da Terra, Universidade Federal do Paraná - UFPR. Curitiba. 210 p.

RIFFEL, S. B. Gamaespectrometria do Granito Serra do Carambeí-PR. 2000. Relatório de Iniciação Científica. (Graduação em Geologia) - Universidade Federal do Paraná - UFPR; Conselho Nacional de Desenvolvimento Científico e Tecnológico - CNPq. Orientador: Francisco José Fonseca Ferreira, 2000.

Gamaespectrometria, aeromagnetometria e susceptibilidade magnética do granito Serra do Carambeí-PR. 2001. Relatório de Iniciação Científica (Graduação em Geologia) - Universidade Federal do Paraná - UFPR; Conselho Nacional de Desenvolvimento Científico e Tecnológico - CNPq, 2001.

RIFFEL, S. B.; FERREIRA, F. J. F.; FORLIN, M.; GUIMARÃES, G. B. Aplicação da Gamaespectrometria (K, eTh, eU) na Caracterização do Granito Serra do Carambeí - PR. In: CONGRESSO BRASILEIRO DE GEOQUÍMICA, 8., eSIMPÓSIO DE GEOQUÍMICA DOS PAÍSES DO MERCOSUL, 1., 2001, Curitiba. Anais... Curitiba: SBGq, 2001.

TAUHATA, L.; SALATI, I. P. A.; DI PRINZIO, R.; DI PRINZIO, A. R.. Radioproteção e dosimetria: fundamentos. 5. ed. Rio de Janeiro: IRD/CNEN, 2003. 263 p.

TURNER, S. P.; REGELORES, M.; KELLEY, S.; HAWKESWORTH, C. J.; MANTOVANI, M. S. $\mathrm{M}$. Magmatism and continental break-up in the South Atlantic: high precision $40 \mathrm{Ar}-39$ Ar geochronology. Earth and Planetary Science Letters, Amsterdam, v. 121, p. 333-348, 1994.

ULBRICH, H. H. G. J.; ULBRICH, M. N. C.; FERREIRA, F. J. F.; ALVES, L. S.; GUIMARÃES, G. B.; FRUCHTING, A. Levantamentos gamaespectrométricos em granitos diferenciados. I: revisão da metodologia e do comportamento geoquímico 
dos elementos K, Th e U. Revista do Instituto de Geociências USP. Série Científica. São Paulo, v. 9, n. 1, p. 33-53, 2009.

WILFORD, J. R.; BIERWIRTH, P. N.; CRAIG, M. A. Application of airborn gamma-ray spectrometry in soil/regolith mapping and applied geomorphology. AGSO Journal of Australian Geology \& Geophysics, v. 17, p. 201-216, 1997.

Recebido em 16/09/10

Aceito para publicação em 19/12/10 


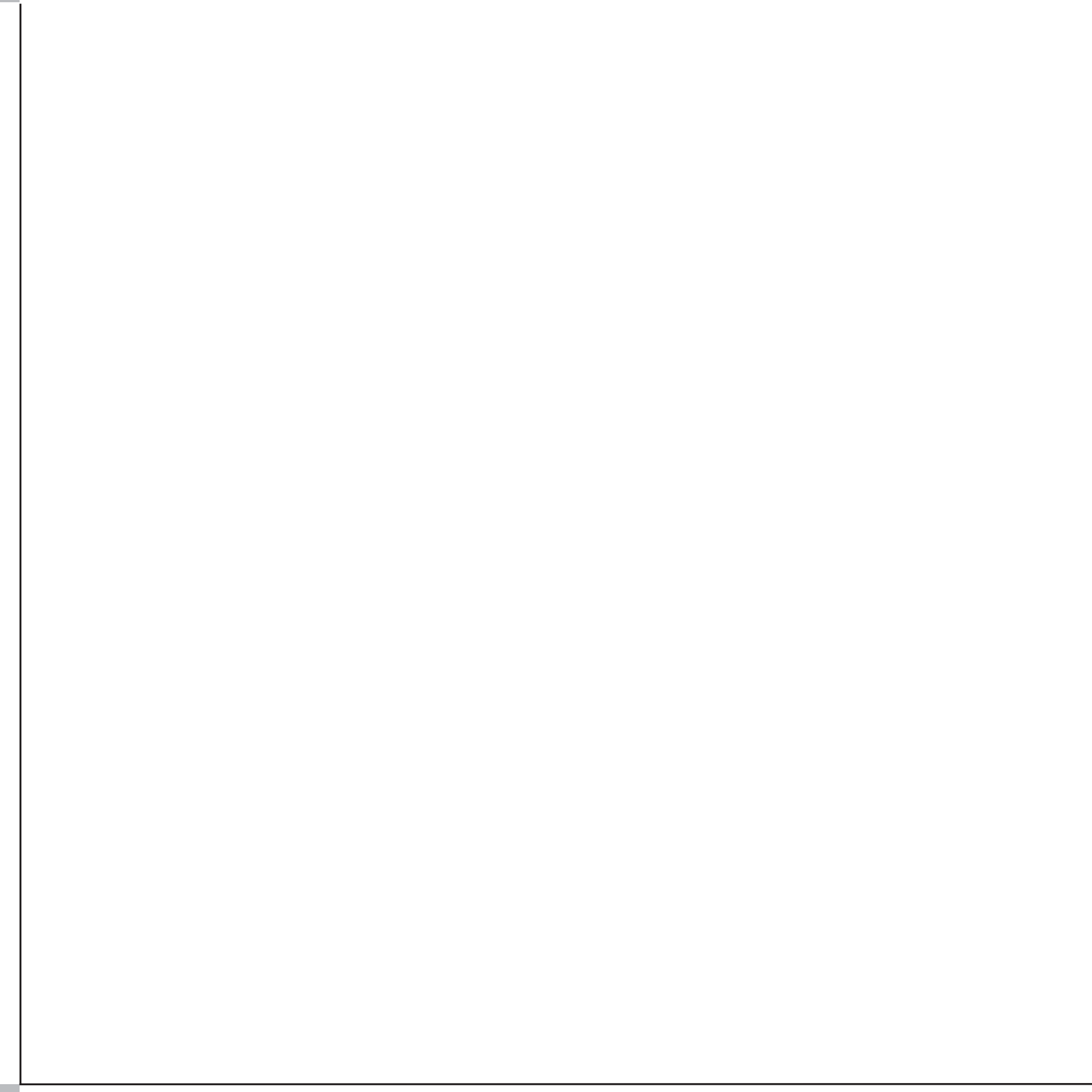

